\title{
Application of yeast in the wastewater treatment
}

\author{
Yan Wang ${ }^{1}$, Liping Qiu ${ }^{1, *}$ and Mengfei $\mathrm{Hu}^{1}$ \\ ${ }^{1}$ School of Civil Engineering and Architecture, University of Jinan, 336 Nanxinzhuang West Road, Jinan, 250022, China
}

\begin{abstract}
Yeast, as a very valuable microbial resource, has a good enzyme system in the body and can adapt to a variety of special environments. Therefore, it plays an important role in the biological treatment of wastewater. The classification and basic characteristics of yeast were introduced, and the application of yeast in the field of wastewater treatment such as high concentration organic wastewater, heavy metal ion wastewater and domestic sewage were summarized. With the mature of yeast technology and the development of science and technology, more techniques such as gene engineering and immobilization technology will be used to treat with yeast, so that it will have a wider application prospect in wastewater treatment.
\end{abstract}

\section{Introduction}

Yeast is a kind of widely distributed eukaryotic microorganism. Because of its fast growth and high metabolic efficiency, it has attracted much attention. In the early 1990s, the Japanese Research Institute realized the application of yeast wastewater treatment technology for the first time in the world. With the deepening of research, the new technologies with yeast as the core have been more and more widely applied in water treatment in recent years[1], and showed great potential and broad prospects. At present, yeasts have been applied in many kinds of industrial wastewater treatment, domestic sewage purification and other fields[2].

\section{The classification and characteristics of yeast}

Yeasts are unicellular fungi, which are usually ovoid, circular or cylindrical. It can be divided into two categories: (1) fermented yeast: a kind of yeast that can only use six-carbon sugar to ferment into alcohol and carbon dioxide[3], mainly used in making bread, steamed bread, and wine-making industry; (2) oxidized yeast: a kind of yeast with strong oxidation ability, weak fermentation ability or no fermentation ability, such as Candida and hansenula polymorpha, mainly used in petroleum processing industry and wastewater treatment process, which is the key target for water treatment. They can utilize many kinds of organic compounds or complex compounds to metabolize[4].

Yeasts usually grow in the acidic environment that $\mathrm{pH}$ is 5.0 6.0, and the optimum growth temperature is $25 \sim 30^{\circ} \mathrm{C}$. They have the characteristics of acid resistance, osmotic pressure resistance, high temperature resistance and high metabolic efficiency. Besides, they have good enzyme system in the body and can adapt to a variety of special environment and are widely distributed in soil, light water, marine and the surface and body of organism. Different populations of yeast are distributed in the different environments, and the changes of community reflect the changes of environmental conditions. Dynowska[5] thought that Trichosporon sp., Rhodotorula sp., Candida sp. and Cryptococcus sp. can be used as indicator fungi for water pollution. In addition, yeasts have strong degradability to some refractory substances and organic poisons. Studies have shown that yeasts can degrade a variety of macromolecular substances, such as phenol[6] and glyceride[7,8].

\section{Application of yeast in water treatment}

At the end of the 1970s, Yoshizawa [9,10] designed a yeast wastewater treatment system. Since then, the unique efficiency of yeast in the treatment of various wastewater has attracted wide attention. With the development of yeast wastewater treatment technology, yeast has been found to produce lipids[11], glycolipids and enzymes[12]. Therefore, it is widely used in the treatment of high concentration organic wastewater, heavy metal ions wastewater and domestic sewage, which has high utilization value.

\subsection{Treatment of high concentration organic wastewater by yeast}

Yeast can convert most of the organic matter into nontoxic and nutritious single cell protein, which has a high efficiency of wastewater treatment[13]. The source of oily wastewater is wide, and the concentrations of COD and BOD are relatively high. If wastewater without treatment enters the water body, it will cause serious environmental pollution. Yeast treatment technology can

\footnotetext{
Corresponding author: lipingqiu@163.com
} 
reduce the oil content in the wastewater from 10000 $\mathrm{mg} / \mathrm{L}$ to $100 \mathrm{mg} / \mathrm{L}$, which is not realized by other biological treatment methods at present. It can make the high concentration organic wastewater clean quickly and save the pretreatment process. Therefore, it is widely used in the treatment of high concentration oilcontaining wastewater[14].

Chigusa et al[15] studied that nine mixed yeast strains isolated from industrial wastewater are used for biological treatment of soybean oil processing wastewater. The device has been running steadily for more than one year. When the influent concentration of $\mathrm{COD}, \mathrm{BOD}_{5}$ and oil are $39300 \mathrm{mg} / \mathrm{L}, 18200 \mathrm{mg} / \mathrm{L}$, and $11900 \mathrm{mg} / \mathrm{L}$, respectively, the removal rate of COD, $\mathrm{BOD}_{5}$ and oil by the wastewater treatment process of yeast was all more than $93 \%$. In recent years, researchers in China have carried out the research work in this field. Zheng's group[16,17] treated high concentration salad oil processing wastewater by yeasts which were separated and screened from the environment. The yeasts removed more than $98 \%$ of oils and $94 \%$ of COD when the concentrations of oil and COD in the raw wastewater were $1500 \sim 1700 \mathrm{mg} / \mathrm{L}$ and $6000 \sim 7000 \mathrm{mg} / \mathrm{L}$ respectively. But because of the existence of fungi silk, the sludge bulking was caused, and the removal rate decreased obviously. When the $\mathrm{C} / \mathrm{N}$ was kept at value of $20 / 1$ in the continuous test, settling ability of sludge has been improved to a certain extent[18].

\subsection{The treatment of heavy metal ion wastewater by yeast}

The removal of heavy metal ions by yeast can be carried out on cell surface and in living cells. The mechanism is complex, mainly including passive adsorption and active adsorption. Zhang et al[19] investigated the effects of adsorption time, temperature, $\mathrm{pH}$ and $\mathrm{Cr}^{6+}$ concentration on the adsorption of $\mathrm{Cr}^{6+}$ by beer yeast. The optimum adsorption conditions were as follows: adsorption time $2 \mathrm{~h}$, temperature $25^{\circ} \mathrm{C}, \mathrm{pH}=2$ and $\mathrm{Cr}^{6+}$ concentration $60 \mathrm{mg} / \mathrm{L}$, and the maximum adsorption rate of $\mathrm{Cr}^{6+}$ was $94.71 \%$. He et al[20] studied the mechanism of enrichment of $\mathrm{Cr}^{6+}$ in wastewater by yeasts. The process of adsorption of $\mathrm{Cr}^{6+}$ by yeasts was accompanied by the release of $\mathrm{K}^{+}, \mathrm{Mg}^{2+}, \mathrm{Na}^{+}, \mathrm{Ca}^{2+}$ and other cations. The ion transport in and out of cells reached balance in $30 \mathrm{~min}$, and the adsorption of $\mathrm{Cr}^{6+}$ approached saturation, which indicated that there was ion exchange between the cations and $\mathrm{Cr}^{6+}$. Han et al[21] used beer yeast for the adsorption of $\mathrm{Cu}^{2+}$ and $\mathrm{Pb}^{2+}$ from wastewater. The experimental results were fit well to the Langmuir and Freundlich model isotherms and the maximum adsorptive quantity of beer yeast were $0.0228 \mathrm{mmol} \mathrm{g}^{-1}$ for $\mathrm{Cu}^{2+}$ and $0.0276 \mathrm{mmol} \mathrm{g}{ }^{-1}$ for $\mathrm{Pb}^{2+}$ according to Langmuir model, respectively. In addition to the above heavy metal ions, yeast has a good adsorption effect on mercury ion, strontium ion and arsenic ion as well as radioactive uranium[22].

\subsection{The treatment of domestic sewage by yeast}

Although the number of yeast in activated sludge is less than that of bacteria, its role can not be ignored. Yeast can be separated from wastewater treatment plant[23]. Different water quality and treatment process have an important influence on the abundance and composition of yeast population. Liu et al[24] studied that identical sewage was treated with anoxic-anaerobic-aerobic process $\left(\mathrm{A}^{2} \mathrm{O}\right)$ and anoxic-aerobic process (AO), respectively, under the same conditions. The results showed that the two systems had similar treatment performance, while there are obvious differences in the yeast community, and there were richer yeast communities in $\mathrm{A}^{2} \mathrm{O}$ than in $\mathrm{AO}$. Meng et al[25] isolated four kinds of low temperature resistantance yeasts from the municipal sewer sediment, and the removal rates of COD by yeasts reached $72 \%-82 \%$.

\section{Development trends}

Yeast has a great advantage in pollutant removal efficiency, which is worth to popularize. As the expanding scope of yeast utilization, the ways and means for the use of yeast are more and more.

\subsection{Technology combined with other strains}

The technology of yeast and other strains was used to treat sewage, making full use of their respective advantages and effectively removing different organic matters in the wastewater. Han et al[7] isolated five yeast strains from the environment. All these strains had higher fatty acid degradation activity with 50\%-90\% removal rate of oil in $1 \mathrm{~d}$ from salad oil manufacturing wastewater composed mainly of fatty acids. While the specific degradation velocity of the wastewater is significantly increased after the mixed culture of five yeast strains, which is about 4-8 times higher than that of single strain. Ling et al[26] studied that the diosgenin wastewater was treated by the yeast and photosynthetic bacteria. Macromolecular substances in diosgenin wastewater could be degraded by yeast firstly, which provides good water quality conditions for the treatment of photosynthetic bacteria in the next step. The total removal rate of $\mathrm{COD}$ could reach $91.2 \%$, while the removal rate of $\mathrm{COD}$ by single yeast and single photosynthetic bacteria is only $34.77 \%$ and $53 \%$, respectively. Ling et al[27] utilized a mixed culture of microalgae and yeasts to treat mixed wastewater from distillery and wastewater treatment plant. Microalgae could produce oxygen for yeasts while yeasts could provide carbon dioxide for microalgae. Yeasts mainly uptaked organic matters and microalgae require nitrogen and phosphorus from wastewater, which greatly improved both lipid production and removal of organic matters and nutrients from wastewater. Lipid content and lipid yield achieved were $63.45 \%$ and $4.60 \mathrm{~g} / \mathrm{L}$, and the removal rates of SCOD, TN, and TP were $95.34 \%$, $51.18 \%$, and $89.29 \%$, respectively, after cultivation of five days.

\subsection{Directional domestication technology}


The new yeast strains can be obtained by using genetic engineering technology, thereby effectively improving the wastewater treatment effect. Wang et al[28] disrupted the MIG1 gene in the oleaginous yeast (the parent yeast), and the disruptant M25 obtained had more lipid bodies than those of its parent yeast. The disruptant M25 contained $48.7 \%$ of oil based on its cell weight, while the parent yeast only contained $36.0 \%$ of oil. However, because of the immature technology, transforming the strains by genetic engineering methods still need to be further studied. The yeast can also be transformed to the dominant yeast strain undergoing directional domestication. Wei et al[29] screened the phenoldegrading yeast strains from activated sludge and bottom sediment by increasing the concentration of phenol gradually. In addition, the studies showed yeast strains with acid resistance, high temperature resistance and high sugar resistance can be obtained under certain acclimation conditions.

\subsection{Biological immobilization technology}

With the development of biological immobilization technology, its application in wastewater treatment has become a new hot spot. Some species of yeasts can form false branching, which is filamentous and very light, and there were a lot of mycelia in the effluent in the operation, and it is difficult to precipitate. If the control is not appropriate, it will be easy to produce a large number of filamentous bacteria and cause the problem of filamentous bacteria expansion, resulting in higher cost of subsequent treatment. At the same time, yeast is prone to autolysis. If it is not recovered in time, it will cause second pollution problem. The immobilization of yeast by strengthening biological carrier technology can not only improve the number and concentration of yeast and ensure the activity of microorganism, but also be easy to be separated and avoid second pollution.

\section{Conclusions}

Through the above researches, it can be seen that yeast can adapt to various kinds of wastewater and bad conditions because of the advantages of acid resistance, osmotic pressure resistance and high metabolic efficiency, so that it can achieve a good removal effect and have a broad prospect. Although the related research started late in China, it has made some progress. In today's world, we should not only consider the great improvement of water quality in wastewater treatment but also maximally recycling resources and realizing energy utilization. In order to make extensive use of yeast wastewater treatment, yeasts should be combined with other more technologies to make it play a greater role.

\section{Acknowledgment}

This work was supported by the National Natural Science Foundation of China (51678276), the key reaearch and development program of Shandong
Province (2016GSF117012, 2016CYJS07A03-3, 2018GSF117026) and the Shandong Provincial Natural Science Foundation (ZR2018BEE040).

\section{References}

1. O.A. Kamanina, D.G. Lavrova, V.A. Arlyapov, V.A. Alferov, O.N. Ponamoreva, Silica sol-gel encapsulated methylotrophic yeast as filling of biofilters for the removal of methanol from industrial wastewater, Enzyme Microb. Technol. 92, 94-98(2016)

2. P. Westlund, V. Yargeau, Investigation of the presence and endocrine activities of pesticides found in wastewater effluent using yeast-based bioassays, Sci. Total Environ. 607-608, 744-751 (2017)

3. S.A. Mohd, R. Abdulla, S. A. Jambo, H. Marbawi, J.A. Gansau, A.M. F. Ainol, F.R. Kenneth, Yeasts in sustainable bioethanol production: A review, Biochemistry and Biophysics Reports 10, 5261(2017)

4. J.L. Wang, Environmental Microorganism $2^{\text {nd }} E d$. (Higher Education Press, Beijing, 2003)

5. M. Dynowska, Yeast-like fungi possessing bioindicator properties isolated from the Lyna river, Acta Mycol. 32, 279-286 (1997)

6. Z.G. Song, G.Y. Wang, X.P. Yue, X.Q. Li, Biodegradation of Phenol and $\mathrm{m}$-Cresol by Candida maltosa, China Water and wastewater 29, 9799(2013)

7. Y. Han, Y. Zhang, Q.X. Yang, M. Yang, W.Z. Lu, Comparison of degradation activities of glyceride and fatty acids of five separated yeast strains, China Environ. Sci. 25, 39-42(2005)

8. M. Hashem, S.A. Alamri, S. Alzomyh, S.A. Alrumman, Biodegradation and detoxification of aliphatic and aromatic hydrocarbons by new yeast strains. Ecotox. Environ. Safe. 151, 28-34(2018)

9. K. Yoshizawa, Treatment of wastewater discharged from a Sake Brewery using yeast, Ferment. Technol., 56, 389-395(1978)

10. K. Yoshizawa, Development of the new treating method of wastewater from food industry using yeast, Nippon Nogeikagaku Kao shi 55, 705711(1981)

11. J. Chung, I. Lee, J.I. Han, Biodiesel production from oleaginous yeasts using livestock wastewater as nutrient source after phosphate struvite recovery, Fuel 186, 305-310(2016)

12. Q.X. Yang, H. Zhang, X.L. Li, Z. Wang, Y. Xu, S.W. Ren, X.Y. Chen, Y.Y. Xu, H.X. Hao, H.L. Wang, Extracellular enzyme production and phylogenetic distribution of yeasts in wastewater treatment systems, Bioresource Technol. 129, 264-273(2013)

13. M. Yang, S.K. Zheng. Pollutant removal-oriented yeast biomass production from high-organicstrength industrial wastewater: A review, Biomass Bioenerg. 64, 356-362(2014) 
14. J.Y. Hu, S.L. Ong, W.J. Ng, F. Lu, X.J. Fan, A new method for characterizing denitrifying phosphorus removal bacteria by using three different types of electron acceptors. Water Res. 37, 3463-3471(2003)

15. K. Chigusa, T. Hasegawa, N. Yamamoto, Y. Watanabe, Treatment of wastewater from oil manufacturing plant by yeasts. Water Sci. Technol. 34, 51-58(1996)

16. S.K. Zheng, M. Yang, F. Liu, Primary studies on laboratory-scale continuous treatment of salad oil manufacturing wastewater by yeasts, China Environ. Sci. 21, 60-63(2001)

17. S.K. Zheng, M. Yang, P.R. Li, Seed yeast cultivation for salad oil manufacturing wastewater treatment, J. Environ. Sci-China 14, 39-43(2002)

18. Y. Han, Q.X. Yang, M. Yang, Y. Zhang, S.K Zheng, Bulking Controls Induced by Nitrogen Insufficiency in Yeast System, Environmental Science 24, 68-72,(2003)

19. C. Zhang, X.S. Luan, W.J. Zhang, S.G. Hou, S.Y. Wang, Biosorption of $\mathrm{Cr}(\mathrm{VI})$ by Immobilized Discarded Brewers Yeast, Food Research and Development 34, 14-17(2013)

20. B.Y. He, H. Yin, H. Peng, J.S. Ye, F. Yang, H.M. Qin, N. Zhang, Cell Physiology Metabolism and Morphology Study of Chromium Biosorption by Yeast, Environmental Science 28, 194-198(2007)

21. R.P. Han, H.K. Li, Y.H. Li, J.H. Zhang, H.J. Xiao, J. Shi. Biosorption of copper and lead ions by waste beer yeast, J. Hazard. Mater. 137,1569-1576(2006)

22. X.Y. Wang, X.Y. Zheng, Y.H. Shen, T.S. Wang, Biosorption kinetics and mechanisms of low concentration uranium by live and heat-killed Saccharomyces cerevisiae, Acta Scien. Circum. 37, 169-177(2017)

23. Q.X. Yang, F.E. Angly, Z. Wang, H. Zhang, Wastewater treatment systems harbor specific and diverse yeast communities, Biochem. Eng. J. 58, 168-176(2011)

24. X.C. Liu, M. Yang, Y. Zhang, X.P. Yang, Y.P. Gan, Microbial community comparison of different biological processes for treating the same sewage, World J. Microbiol. Biotechnol. 23, 135-143(2007)

25. .X.Z. Meng, A.X. Jiang, R.Y. Zhao, Z.F. Wang, Study on sewage water treatment in cold area by low temperature-resistant yeast, Journal of Harbin University of C.E. and Architecture 33, 70-73(2000)

26. Y. Ling, G.Y. Feng, J.D. Liu, D. Zhu, W.B. Shen, X.G. Li, Studies on Application of Yeastphotosynthetic Bacteria to Treatment of Diosgenin Wastewater, Acta Agric. Boreali-occidentalis Sinica 15, 109-112(2006)

27. J.Y. Ling, S. Nip, W.L. Cheok, R.A. de Toledo, H. Shim, Lipid production by a mixed culture of oleaginous yeast and microalga from distillery and domestic mixed wastewater, Bioresource Technol. 173,132-139(2014)

28. Z.P. Wang, H.M. Xu, G.Y. Wang, Z. Chi, Z.M. Chi,
Disruption of the MIG1 gene enhances lipid biosynthesis in the oleaginous yeast Yarrowia lipolytica ACA-DC 50109, Biochim. Biophys. Acta 1831, 675-682(2013)

29. W. Wei, M. Li, J.L. Dong, H. Xiang, X.C. Du, Domestication, Screening and Performance Study of Phenol-Degrading Yeasts, Journal of Shenyang Jianzhu University (Natural Science) 29, 11221127(2013) 